\title{
Cerrahi ünitemizde yapılan kolonoskopik polipektomilerin histopatolojk sonuçları
}

\section{Histopathological results of colonoscopic polypectomy in a surgery unit}

\author{
Ayetullah TEMIZ ${ }^{1}$, Abdülkadir KAYA² \\ ${ }^{1}$ Erzurum Bölge Eğitim ve Araştırma Hastanesi, Genel Cerrahi Kliniği, Erzurum \\ ${ }^{2}$ Adilcevaz Onkoloji Hastanesi, Aile Hekimliği Birimi, Bitlis
}

\begin{abstract}
Giriş ve Amaç: Kolorektal kanserlerin \%95'inden fazlası adenomatöz polipten orijin alır. Kanserlerin büyük bir çoğunluğu normal görünümlü mukozadan adenomaya, displaziye ve nihai olarak karsinoma geçiș göstmektedir. Biz bu çalışmada cerrahi ünitemizde yapılan kolonoskopik polipektomilerin histopatolojik özelliklerini irdelemeyi amaçladık. Gereç ve Yöntem: Erzurum Bölge Eğitim ve Araştırma Hastanesi Cerrahi Endoskopi ünitesinde Ocak2013 ile Aralık-2015 yılları arasında kolonoskopik polipektomi yapılan hastaların verileri bölümümüz bilgi işlem veritabanından retrospektif olarak tarand1. Bulgular: Hastalarımızda polip görülme oranı \%16,1 idi. Hastala-

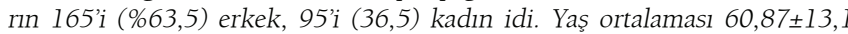
(24-93) idi. Lokalizasyona göre polipler \%42, I'i sigmoid kolon ve \%29,6's1 rektumda idi. Histopatolojik değerlendirmede, poliplerin \%49,5’i neoplastik polip idi. Bu poliplerin \%40,2'si tübüler adenom, \%4,4'ü tübülovillöz adenom, \%0,6'sı villöz adenom, \%1,2'si intramukozal karsinom, \%3,1'i adenokarsinom idi. Adenomatöz poliplerin 52'sinde (\%33) displazi izlendi. Bunların 48'i (\%92) düşük dereceli displazi, 4'ü (\%3) yüksek dereceli displazi idi. Polip çapı ile displazi arasında pozitif korelasyon izlendi $(p=0,038)$. Yüksek dereceli displazi görülen hastaların tümü 50 yaş üstü hastalardı. Fakat genç hastalarda total displazi oranı daha yüksekti ve istatistiksel olarak anlamlı idi ( $P=0,005)$. Sonuç: Biz bu çalışmada kanser öncüsü olan adenomatöz poliplerde, literatür ile uyumlu olarak polip çapının displazi ile pozitif korelasyon gösterdiğini, total displazinin genç hastalarda, yüksek dereceli displazinin de yaşlı hastalarda daha yüksek olduğunu tespit ettik.
\end{abstract}

Anahtar kelimeler: Polip, adenom, displazi
Background and Aims: More than 95\% of colorectal cancers are of adenomatous polyps origin. A large majority of cancers undergo a transition from normal-looking mucosa to adenoma, dysplasia, and eventually carcinoma. In this study, we aimed to investigate the histopathologic features of colonoscopic polypectomy performed in our surgical unit. Materials and Methods: The data from patients who underwent colonoscopic polypectomy between January 2013 and December 2015 in the surgical endoscopy unit at Erzurum Regional Training and Research Hospital were scanned retrospectively from our department data processing database. Results: The rate of polyps in our patients was $16.1 \%$. One hundred and sixty-five $(63.5 \%)$ of the patients were male, and 95 (36.5\%) were female. The mean age was $60.87 \pm 13.1$ years (2493 years old). According to polyp location, $42.1 \%$ were in the sigmoid colon, and $29.6 \%$ were in the rectum. On histopathological evaluation, $49.5 \%$ of the polyps were neoplastic polyps. Tubular adenomas were found in $40.2 \%$, tubulovillous adenomas in $4.4 \%$, villous adenomas in $0.6 \%$, intramucosal carcinomas in 1.2\%, and adenocarcinomas in 3.1\% of these polyps. Dysplasia was observed in 52 (33\%) of adenomatous polyps. Of these, 48 (92\%) were low-grade dysplasia, and 4 (3\%) were high-grade dysplasia. A positive correlation was observed between polyp diameter and dysplasia $(p=0.038)$. All of the patients with high-grade dysplasia were over 50 years old. However, the rate of total dysplasia was higher in younger patients and was statistically significant $(p=0.005)$. Conclusion: In this study, we found that polyp diameter correlates positively with dysplasia in adenomatous polyps, which are cancer precursors, and that total dysplasia is higher in young patients and high-grade dysplasia in elderly patients.

Key words: Polyp, adenoma, dysplasia

göstermiştir (3-5). Kanserlerin \%95'inden fazlası adenomatöz polipten orijin alır. KRK’lerin büyük bir çoğunluğu normal görünümlü mukozadan adenoma, displazi ve nihai olarak karsinoma geçiş gösteren sıralı yolakla meydana gelir. Genelde 50 yaşından sonra adenomatöz polipler sıklıkla görülmekle beraber poliplerin büyük bir çoğunluğu adenokarsinoma ilerlemez (6). Dünya Sağlık Örgütü ve Sağlık Bakanlığı da semptomsuz hastalarda KRK taramaları için 50 yaşından itibaren tarama kolonoskopisi'ni önermektedir. Kolonoskopi ile kolonik mukozanın direk görülmesi; biyopsi olanağı, polip ve lokal tümörlerin çıkarılmasına olanak sağlaması ile diğer tarama testlere göre avantajlıdır. Amerikan Gastroenteroloji Koleji kolonoskopiyi ulaşılabilirliğinin olduğu yerlerde tercih edilen tarama testi olarak belirtmektedir (7). Biz bu çalışmada 
Erzurum ve bölgesine hitap eden cerrahi ünitemizde yapılan kolonoskopik polipektomilerin histopatolojik özelliklerini irdelemeyi amaçladık.

\section{GEREC ve YÖNTEM}

Erzurum Bölge Eğitim ve Araştırma Hastanesi Cerrahi endoskopi ünitesinde Ocak-2013 ile Aralık-2015 ylları arasinda kolonoskopik polipektomi yapilan hastaların verileri bölümümüz bilgi işlem veritabanından retrospektif olarak tarandı. 10'dan fazla polip görülen hastalar, tıkayıcı kitleler ve daha önce kolorektal kanser tanısı alan hastalar değerlendirmeye alınmadı. Çalışmamızdaki hastalardan endoskopi işlemi öncesi aydınlatılmış yazılı onam alındı. Kolonoskopi işlemi için randevu verilen tüm hastalara, standart olarak 3 gün öncesinden posasız sulu gıda rejimine başlandı. İşlemden bir gün önce 2 adet X-M (Sennozid A+B) laktasif solüsyon oral yoldan, işlem sabahı 2 adet BT, Enema (sodyum dihidrojen fosfat+dihidrojen fosfat) rektal yoldan verilerek barsak temizliği yapıldı. Tüm kolonoskopik işlemler Fujinon Corporation markalı videoskopla yapildı. Toplam 1.618 hastaya kolonoskopi yapildı. 260 hastada 321 adet kolonoskopik polipektomi işlemi gerçekleştirildi. Hastalara ait demografik bilgiler (yaş, cinsiyet) kolonoskopi raporundaki polip lokalizasyonu, çapı, sayısı ve polibin saplı olup olmadığı ile patoloji raporundaki polibin histopatolojik tanısı ve özellikleri hastanemiz bilgisayar kayıtlarından bulunarak kayıt altına alındı.

Hastaların verileri SPSS Windows 21.0 programına kaydedilerek istatistiksel analizler gerçekleştirildi ve $\mathrm{p}<0.05$ istatistiksel olarak anlamlı kabul edildi.

\section{BULGULAR}

Hastalarımızda polip görülme oranı \%16,1 idi. Hastaların 165 'i $(\% 63,5)$ erkek, 95’i $(36,5)$ kadın idi. Yaş ortalaması $60,87 \pm 13,1$ (24-93) idi. Lokalizasyona göre poliplerin \%1,9’u çekum, \%1,6' sı çıkan kolon, \%0,6'sı hepatik fleksura, \%8,1'i transvers kolon, \%2,2'si splenik fleksura, \%13,4'ü inen kolon, \%42,1'i sigmoid kolon, \%29,6'sı rektum, \%0,6's1 anal kanaldan çıarıldı (Tablo 1). Histopatolojik değerlendirmede, poliplerin \%49,5'i neoplastik polip idi. Bu poliplerin \%40,2'si tübüler adenom, \%4,4’ü tubülovillöz adenom, \%0,6'sı villöz adenom, \%1,2'si intramukozal karsinom, \%3, 1'i adenokarsinom idi. Adenomatöz poliplerin 52'sinde (\%33) displazi izlendi. Bunların 48'i (\%92) düşük dereceli displazi, 4’ü (\%3) yüksek dereceli displazi idi. Neoplastik olamayan poliplerin oranı \%50,5 idi. Bunların \%34' ü hiperplastik polip, \%4'ü serrated adenom, \%3,7'si juvenil polip, \%6,2'si enflamatuvar polip, \%1,9'u normal kolon yüzeyi, \%0,3'ü lipom ve $\% 0,3$ 'ü lenfoid polip olarak rapor edildi (Tablo.2). Poliplerin $\% 67$ 'si 1 adet, \%19,3'ü 2 adet, \%9,7'si 3 adet, \%2,5’i 4 adet, \%1,6'sı 5 adet idi. Poliplerin \%48,6'sı küçük çaplı (0-5 mm), $\% 32,1$ 'i orta çaplı (6-10 mm) ve \%19,3'ü büyük çaplı (10 mm'den büyük) idi. Poliplerin \%57,9'u sapl, \%42, l'i sapsız idi. Displazi saptanan poliplerin oranı, küçük çaplı polipler- de $(0-5 \mathrm{~mm}) \% 25$, orta çaplı poliplerde $(6-10 \mathrm{~mm}) \% 44$ ve büyük çaplı poliplerde (10 mm'den büyük) \%47 olarak izlendi. Polip çapı ile displazi arasında pozitif korelasyon izlendi $(\mathrm{p}=0,038)$. Displazi ile polibin sayısı, lokalizasyonu ve sapı arasında istatistiksel olarak anlamlı fark izlenmedi. 50 yaş üstü hastalarda adenomatöz poliplerin görülme oranı $\% 47,3$ iken 50 yaş ve altı hastalarda oran \%37,5 idi. Malign poliplerin görülme oranı 50 yaş üstü hastalarda $\% 4,8$ iken 50 yaş ve altı hastalarda oran $\% 2,7$ idi. 50 yaş üstü hastalarda adenomatöz poliplerde displazi görülme oranı $\% 30$ iken 50 yaş ve altı hastalarda oran \%70 idi. Yüksek dereceli displazi görülen hastaların tümü 50 yaş üstü hastalardı. Fakat genç hastalarda total displazi oranı daha yüksekti ve istatistiksel olarak anlamlı idi $(\mathrm{p}=0,005)$ (Tablo 3).

Tablo 1. Kolondaki polip yerleşim yerine göre dağlımı

\begin{tabular}{lcc} 
Polip Lokalizasyonu & Sayı (n) & Yüzde (\%) \\
Çekum & 6 & 1,9 \\
Çıkan kolon & 5 & 1,6 \\
\hline Hepatik fleksura & 2 & 0,6 \\
\hline Transvers kolon & 26 & 7,1 \\
\hline Splenik fleksura & 7 & 2,2 \\
\hline Inen kolon & 43 & 13,4 \\
\hline Sigmoid kolon & 135 & 42,1 \\
\hline Rektum & 95 & 29,6 \\
\hline Anal kanal & 2 & 0,6 \\
Toplam & 321 & 100
\end{tabular}

Tablo 2. Kolonoskopik polipektomi yapılan olguların histopatolojik sonuçları

\begin{tabular}{|lcc|}
\hline Histopatolojik Tanı & Sayı (n) & Yüzde (\%) \\
\hline Neoplasik Polipler & 159 & 49,5 \\
\hline Tübüler adenom & 129 & 40,2 \\
\hline Tübülovillöz adenom & 14 & 4,4 \\
\hline Villöz adenom & 2 & 0,6 \\
\hline Intramukozal karsinom & 4 & 1,2 \\
\hline Adenokarsinom & 10 & 3,1 \\
\hline Neoplastik olmayan polipler & 162 & 50,5 \\
\hline Serrated adenom & 13 & 4,0 \\
\hline Hiperplastik polip & 109 & 34,0 \\
\hline Juvenil polip & 12 & 3,7 \\
\hline Enflamatuar polip & 20 & 6,2 \\
\hline Normal kolon yüzeyi & 6 & 1,9 \\
\hline Lipom & 1 & 0,3 \\
\hline Lenfoid & 1 & 0,3 \\
\hline Toplam & 321 & 100 \\
\hline
\end{tabular}




\section{TARTIŞMA}

Kolon ve rektum mukozasından lümene çıkıntı yapan normal dışı tüm yapılar polip olarak adlandırılır. Doğrudan mukozadan kaynaklanmayan kitleler de mukozayı kabartarak polip görüntüsü oluşturabilirler. Bu tür lezyonları da genellikle polipoid lezyon şeklinde tanımlamak uygundur. Kolonoskopi sırasında saptanan poliplerin boyutuna bakılmaksızın potansiyel kanser nedeniyle çıkartılması ve patolojik tanısının konması önerilmektedir. Polipler histolojik olarak neoplastik veya non- neoplastik olarak siniflandırılırlar. Ayrıca polipler saplı veya sapsız, tek veya birden fazla olabilirler. Polipler klinik olarak genelikle asemptomatik olmakla beraber bazen rektal kanama, demir eksikliği anemisi görülürken, sol kolon yerleşimli büyük poliplerde hasta obstrüksiyon ile gelebilmektedir. Sıklıkla sol kolon ve rektumda görülürler.
Yaptığımız çalışmada polip görülme oranı \%16,1 idi. Hastaların 165'i $(\% 63,5)$ erkek, 95'i $(36,5)$ kadın idi. Lokalizasyona göre polipler en çok \%42, 1'i sigmoid kolon ve \%29,6'sı rektumda lokalize idi. Yapılan bir çalışmada 675 olguluk bir seride \%47 sigmoid kolon, \%18,7 inen kolon, \%13,6 transvers kolon, \%12,5 rektumda polip olduğu bildirilmiştir (8). Yine ülkemizde yapılan bir çalışmada \%47.0 rektosigmoid, \%19.3 inen kolon, \%11.2 transvers kolon, \%8.5 çıkan kolon ve \%4.6 çekumda polip saptandığı bildirilmiştir (9). Bu sonuçlar ile karşılaştırıldığında, bizim çalışmamızdaki poliplerin kolondaki dağılımının literatür ile uyumlu olduğu görüldü.

Prekanseröz polipler olarak kabul edilen neoplastik polipler tüm poliplerin yaklaşık 2/3'ünü oluşturmakta olup villöz dokuya göre sinıflandırılır. Villöz dokusu olmayan polipler tübüler adenom, villöz doku ve tübüler dokusu beraber olan poliplere tübülovillöz adenom ve tamamen villöz dokudan

Tablo 3. Kolonoskopik polipektomi yapılan olgularda adenomatöz poliplerde displazi gelişen poliplerin özellikleri

\begin{tabular}{|c|c|c|c|c|c|}
\hline & & Displazi Yok n (\%) & Displazi Var n (\%) & Toplam & P değeri \\
\hline \multirow[t]{2}{*}{ Cinsiyet } & Erkek & $56(\% 59)$ & $39(\% 41)$ & 95 & 0,072 \\
\hline & Kadın & $37(\% 74)$ & $13(\% 26)$ & 50 & \\
\hline \multirow[t]{2}{*}{ Yaş } & 50 yaş ve altı & $11(\% 40)$ & $82(\% 70)$ & 93 & 0,005 \\
\hline & 50 yaş üstü & $16(\% 60)$ & $36(\% 30)$ & 52 & \\
\hline \multirow[t]{3}{*}{ Patoloji } & Tübüler adenom & $83(\% 64)$ & $46(\% 36)$ & 129 & 0,196 \\
\hline & Tübülovillöz adenom & $9(\% 64)$ & $5(\% 36)$ & 14 & \\
\hline & Villöz adenom & $1(\% 50)$ & $1(\% 50)$ & 2 & \\
\hline \multirow[t]{9}{*}{ Lokalizasyon } & Çekum & $3(\% 75)$ & $1(\% 25)$ & 4 & 0,639 \\
\hline & Çıkan kolon & $1(\% 33)$ & $2(\% 66)$ & 3 & \\
\hline & Hepatik fleksura & $2(\% 100)$ & $0(\% 0)$ & 2 & \\
\hline & Transvers kolon & $4(\% 44)$ & $5(\% 46)$ & 9 & \\
\hline & Splenik fleksura & $3(\% 75)$ & $1(\% 25)$ & 4 & \\
\hline & Inen kolon & $15(\% 60)$ & $10(\% 40)$ & 25 & \\
\hline & Sigmoid kolon & $45(\% 69)$ & $20(\% 39)$ & 65 & \\
\hline & Rektum & $19(\% 59)$ & $13(\% 41)$ & 32 & \\
\hline & Anal kanal & $1(\% 100)$ & $0(\% 0)$ & 1 & \\
\hline \multirow[t]{5}{*}{ Polip sayısı } & 1 adet & $64(\% 66)$ & $33(\% 34)$ & 97 & 0,763 \\
\hline & 2 adet & $13(\% 56)$ & $10(\% 44)$ & 23 & \\
\hline & 3 adet & $12(\% 67)$ & $6(\% 33)$ & 18 & \\
\hline & 4 adet & $3(\% 50)$ & $3(\% 50)$ & 6 & \\
\hline & 5 adet & $1(\% 100)$ & $0(\% 0)$ & 1 & \\
\hline \multirow[t]{3}{*}{ Polip çapı } & $0-5 \mathrm{~mm}$ & $49(\% 75)$ & $16(\% 25)$ & 65 & 0,038 \\
\hline & $6-10 \mathrm{~mm}$ & $27(\% 56)$ & $21(\% 44)$ & 48 & \\
\hline & 10 mm'den büyük & $17(\% 53)$ & $15(\% 47)$ & 32 & \\
\hline \multirow[t]{2}{*}{ Polip sapı } & Saplı & $55(\% 62)$ & $34(\% 38)$ & 89 & 0,348 \\
\hline & Sapsız & $38(\% 68)$ & $18(\% 32)$ & 56 & \\
\hline Toplam & & $93(\% 64)$ & $52(\% 36)$ & 145 & \\
\hline
\end{tabular}


oluşan poliplere villöz adenom denilmektedir. Adenomatöz poliplerin \%80-86'sını tübüler adenomlar, \%3-16'sını villöz adenomlar ve \%8-16'sını tübülovillöz adenomlar olușturmaktadır $(8,10)$. Bu adenomların \%5'i kansere dönüşebilmektedir. Bizim çalışmamızda poliplerin \%49,5'i neoplastik polip idi. Bu poliplerin $\% 40,2$ 'si tübüler adenom, $\% 4,4$ 'ü tubülovillöz adenom, \%0,6’sı villöz adenom, \%1,2'si intramukozal karsinom, \%3,1’i adenokarsinom idi.

Adenomdan kansere dönüşümde en önemli histopatoloji gösterge displazi derecesidir. Villöz histoloji, artmış polip boyutu yüksek dereceli displazi ve polip sayısındaki artış kanser için risk faktörleridir. Özellikle displazi derecesi yüksek adenomlarda kansere progresyon riski daha yüksektir $(9,11)$. Yapılan çalışmalarda adenomatöz polipte düşük dereceli displazi oranı \%19-20,8, yüksek dereceli displazi oranı \%6,7-8 olarak bildirilmiştir $(9,12)$. Çalışmamızdaki adenomatöz poliplerdeki düşük dereceli displazi oranı \%33, yüksek dereceli displazi oranı \%3 olarak bulunmuştur.

Yapılan çalışmalarda polip çapı artıkça displazi gelişimi ve malignite riski artmakta ve $2 \mathrm{~cm}$ veya daha büyük poliplerde malignite riskinin \%10'dan fazla olduğu bildirilmektedir (13). Yine ülkemizde yapılan bir çalışmada displazi saptanmayan neoplastik olmayan poliplerin ortalama çap $15.3 \pm 3.0$ mm iken, düşük derece displazi mevcut olan olguların ortalama polip çapı $6.4 \pm 4.0 \mathrm{~mm}$, yüksek derece displazi saptanan poliplerin ortalama çapı $7.9 \pm 5.0 \mathrm{~mm}$ olarak saptandığı, polibin çapı ile displazi arasında pozitif korelasyon olduğu gösterilmiştir (14). Yaptığımız çalışmada displazi saptanan

\section{KAYNAKLAR}

1. Winawer SJ. The multidisciplinary management of gastrointestinal cancer. Colorectal cancer screening. Best Pract Res Clin Gastroenterol 2007;21:1031-48.

2. Sağlık Bakanlığı Kanserle Savaş Dairesi Başkanlığı 2006-2008 Yllları Türkiye Kanser Insidans1, www.kanser.gov.tr

3. Kolorektal polipler ve polipozis sendromları. Tözün N, Simșek H, Özkan H, Şimşek I, Gören A, (Eds) Klinik Gastoenteroloji ve Hepatoloji. Medikal ve Nobel Yaymcillk, 2007:963-70.

4. Dolar E, editör. Kolorektal Tümörler. Nobel ve Güneş Yayınları. 2005 400-8.

5. Eddy DM. Screening for colorectal cancer. Ann Intern Med 1990;113:373-84.

6. Levin B, Lieberman DA, McFarland B, et al. Screening and surveillance for the early detection of colorectal cancer and adenomatous polyps 2008: a joint guideline from the American Cancer Society, the US Multi -Society Task Force on Colorectal Cancer,and the American College of Radiology. Gastroenterology 2008;134:1570-95.

7. Rex DK1, Johnson DA, Anderson JC, et al; American College of Gastroenterology. American College of Gastroenterology guidelines for colorectal cancer screening 2009. Am J Gastroenterol 2009;104:739-50.

8. Konishi F, Morson BC. Pathology of colorectal adenomas: A colonoscopic survey. J Clin Pathol 1982;35:830-41.

9. Eminler AT, Sakallı M, Irak K, et al. Gastroenteroloji ünitemizdeki kolonoskopik polipektomi sonuçlarımı. Akademik Gastroenteroloji Dergisi 2011;10:112-5.

10. O'Brien MJ, Winaver SJ, Zauber AG, et al. The National Polyp Study: Patient and polyp characteristics associated with high-grade dysplasia in colorectal adenomas. Gastroenterology 1990;98:371-9. poliplerin oranı, küçük çaplı poliplerde (0-5 mm) \%25, orta çaplı poliplerde (6-10 mm) \%44 ve büyük çaplı poliplerde (10 mm'den büyük) \%47 olarak izlendi. Polip çapı ile displazi arasında pozitif korelasyon izlendi $(\mathrm{p}=0,038)$.

Adenomlarda yaş artıkça polip görülme sıklı̆̆ı, büyüklüğü ve displazi gelişme oranı artmaktadır (15-17). Yapılan çalışmalarda genç hastalarda düşük dereceli displazi oranı daha yüksekken yaş arttıkça yüksek dereceli displazi oranı da artmaktadır $(18,19)$. Bizim çalışmamızda 50 yaş üstü hastalarda adenomatöz poliplerin görülme oranı \% 47,3 iken 50 yaş ve altı hastalarda oran \%37,5 idi. Malign poliplerin görülme oranı 50 yaş üstü hastalarda \% 4,8 iken 50 yaş ve altı hastalarda oran $\% 2,7$ idi. 50 yaş üstü hastalarda adenomatöz poliplerde displazi görülme oranı \%30 iken 50 yaş ve altı hastalarda oran \%70 idi. Yüksek dereceli displazi görülen hastaların tümü 50 yaş üstü hastalardı. Fakat genç hastalarda total displazi oranı daha yüksekti ve istatistiksel olarak anlamlı idi $(\mathrm{p}=0,005)$.

Sonuç olarak Doğu Anadolu Bölgemizin geniş kesimine hizmet veren endoskopi ünitemizde kolorektal polipler ve adenomatöz poliplerdeki displazi ayrıntıları ile irdelenmiştir. Biz bu çalışmada kanser öncüsü olan adenomatöz poliplerde, literatür ile uyumlu olarak polip çapının displazi ile pozitif korelasyon gösterdiğini ve total displazinin genç hastalarda, yüksek dereceli displazinin de yaşlı hastalarda daha yüksek olduğunu tespit ettik. Özellikle displazi saptanan olgulardaki prognozun ortaya konması için geniş çaplı çalışmalara ihtiyaç vardir.

11. Heitman SJ, Ronksley PE, Hilsden RJ, et al. Prevalence of adenomas and colorectal cancer in average risk individuals: a systematic review and meta-analysis. Clin Gastroenterol Hepatol 2009; 7:1272-8.

12. Weinberg DS. Large adenoma recurrence after polypectomy. Gastrointest Endosc 2009;70:350-2.

13. Korkmaz H, Kendir IC, Akkaya Ö. Evaluation of size, localization and histopathologic structures of colonic polyps. Endoscopy Gastrointestinal. 2016;(24):13-17.

14. Oymacı E, Sarı E, Uçar AD, et al. Cerrahi endoskopi ünitemizdeki kolonoskopik polipektomi sonuçlarımızın değerlendirilmesi. Kolon Rektum Hast Derg 2014;24:118-24.

15. Williams AR, Balasoorriya BAW, Day DW. Polyp and cancer of the large bovel: A necropsy study in Liverpool. Gut 1982;23:835-42.

16. Vatn MH, Staisberg H. The prevalence of polyps of the large intestine in Osio: An autopsy study. Cancer 1982;49:819-25.

17. Eide TJ. The age, sex and site sifesific occurence of adenomas and carcinomas of the large intestine within a defined population. Scand J Gastroenterol 1986;21:1083-8

18. Cekodhima G, Cekodhima A, Beqiri A, et al. Demographic and histopathological characteristics of colorectal polyps: a descriptive study based on samples obtained from symptomatic patients. Zdrav Var 2016;55:118-23

19. Qureshi A, Shihi SA, Ali Z, Shalaby A. A retrospective study of clinico-pathological characteristics of colonic polyps in adults seen at a tertiary care centre. JPMA. J Pak Med Assoc 2017;67:12-4. 